\title{
Data-driven study on individual occupant comfort using heating setpoints and window openings in new low-energy apartments - preliminary insights
}

\author{
Lucile Sarran ${ }^{1, *}$, Morten Herget Christensen ${ }^{2}$, Christian Anker Hviid ${ }^{1}$, Andrea Marin Radoszynski ${ }^{2}$, Carsten Rode $^{1}$, \\ and Pierre Pinson ${ }^{2}$ \\ ${ }^{1}$ Department of Civil Engineering, Technical University of Denmark, Kongens Lyngby, Denmark \\ ${ }^{2}$ Department of Electrical Engineering, Technical University of Denmark, Kongens Lyngby, Denmark
}

\begin{abstract}
This work suggests a method to evaluate residential building occupants' neutral temperature in winter based on their interaction with their heating system.

This study applies the developed method on eight new, low-energy apartments in Copenhagen, Denmark. A set of indoor temperature, heating setpoint, window opening and floor heating valve opening data was collected from mid-January to the end of April, spanning through a large part of the Danish heating season. Semi-structured interviews were performed with occupants of three of the eight apartments in order to understand their use of their heating system.

This preliminary study permits to highlight the potential and the current limitations of the proposed method, both for neutral temperature estimation as such and for applications in optimizing the energy flexibility provided by the building. This article suggests directions for further elaboration of the model. The main two influential factors highlighted here affecting setpoint adjustment are the occupants' acceptability of temperature variation and their ability to control the heating system.
\end{abstract}

\section{Introduction}

The residential building sector accounted for $26 \%$ of the final energy consumption of the European Union in 2016 [1]. The need to reduce the residential energy consumption has led in Denmark to stricter building regulations, and consequently to the appearance of new low-energy residences sharing certain characteristics: high levels of insulation and airtightness, large thermal mass, large glazed surfaces, as well as energy-saving building systems such as floor heating [2].

These new residential buildings are also expected in a close future to tackle the issue of the stability of energy systems including a high share of renewable energy generation. Buildings, because of their large energy consumption and their thermal inertia, are increasingly seen as a source of flexibility for the energy grid. For this to be possible, the distribution system operators must be able to know with a given certainty when and for how long households need to consume energy before occupants' comfort starts to degrade - which implies that the latter must be accurately defined.

However, it is widely recognized that there exists a gap between the predicted energy consumption of a building and its actual consumption once in use, and that occupant behavior bears a large responsibility in this gap $[3,4]$. Preferences in terms of indoor conditions are indeed extremely variable from person to person and from dwelling to dwelling $[5,6]$. Moreover, new building system types, seldom present in older houses and apartments, are unknown to many occupants. They are sometimes perceived as being more complex to use than their predecessors [7].

There is therefore a critical need for a method to investigate building inhabitants' comfort preferences at the individual level, in order to be able to design flexibility strategies that do not threaten occupants' comfort and well-being.

Defining occupants' comfort temperature range is mostly studied in a statistical way, starting from Fanger's PMV model [8]. The adaptive comfort theory [9] focuses mainly on office buildings, but some studies have also been made on residential cases, showing a wider and in some places lower comfort range than in offices [10, 11]. The adaptive theory has also been adapted to winter conditions by Peeters et al. [12]. Both PMV and adaptive theories intend to define the indoor conditions that are accepted by the majority in a large population, but do not go down to the individual occupant's level.

On the contrary, personal comfort models, such as those detailed by Kim et al. [13], aim at being applicable to any individual occupant. Most of them are directed towards office spaces and rely on indoor climate measurements combined with thermal sensation questionnaires [14-16], which can only be administered in relatively small samples and can be quite intrusive.

With the emergence of smart thermostats, a large amount of insider data is potentially available about

${ }^{*}$ Corresponding author: lucjsar@byg. dtu.dk 
occupants' actual comfort-regulating actions, permitting a better understanding of their individual thermal comfort preferences. Huchuk [17] collected indoor climate data as well as setpoint data from over 10.000 ecobee smart thermostats and concluded on the effect of seasons and climate region on users' preferences. Setpoint changes can in addition be used as an indicator of thermal discomfort, as done by Wyon et al. [18] in a covert field study: the impact of a disabled heat pump controller on occupants' thermal comfort was evaluated by comparing the total number of heating setpoint adjustments during that week to that of a prior week. We believe that such a resource could be used further to improve the existing understanding of occupant comfort in homes and operate building systems accordingly in a flexible way.

This study presents a method to evaluate occupants' neutral temperature in winter based on their interaction with heating systems, together with an analysis of potential biases coming from non-optimal use, window opening and other adaptive strategies. The consequences of this behavior on the apartments' flexibility potential is also presented. The case study is a new apartment building located in Copenhagen, Denmark. This paper presents a preliminary investigation carried out on several apartments in this building, comprising both sensor data collection and semi-structured interviews.

\section{Methods}

\subsection{Case study building and apartments}

The case study building is an apartment block located in Nordhavn, Copenhagen, Denmark, that has been occupied since October 2017. Eight apartments were chosen, located on the same side of the building and therefore with similar orientation (Fig. 1). For reasons of confidentiality, the apartments and their respective occupants will here be called Apartment / Occupant A, B..., H, and the use of the feminine gender will be used for all occupants. The apartments have a similar structure but present some differences, seen on Table 1 and Fig. 1. The apartments are equipped with floor heating in all rooms. In each room, heating is controlled via a screen located by the door displaying the indoor temperature as well as an adjustable setpoint. When the setpoint is higher than the indoor temperature by at least $0.5^{\circ} \mathrm{C}$, a pictogram appears and the floor heating valve opens. Moreover, the screen in each room also displays the local $\mathrm{CO}_{2}$ concentration and relative humidity.

The balcony door in the living room is equipped with a sensor recording door openings; when the door is opened, instruction is given to the heating system to

Table 1. Overview of the investigated apartments

\begin{tabular}{|l|c|c|c|c|c|c|c|c|}
\hline Apartment & A & B & C & D & E & F & G & H \\
\hline Living room type & 1 & 2 & 1 & 1 & 1 & 1 & 1 & 1 \\
\hline Floor & 4 & 0 & 1 & 0 & 2 & 4 & 5 & 5 \\
\hline $3^{\text {rd }}$ bedroom & No & No & Yes & No & No & Yes & Yes & No \\
\hline Extra room above & No & No & No & No & No & No & Yes & Yes \\
\hline
\end{tabular}
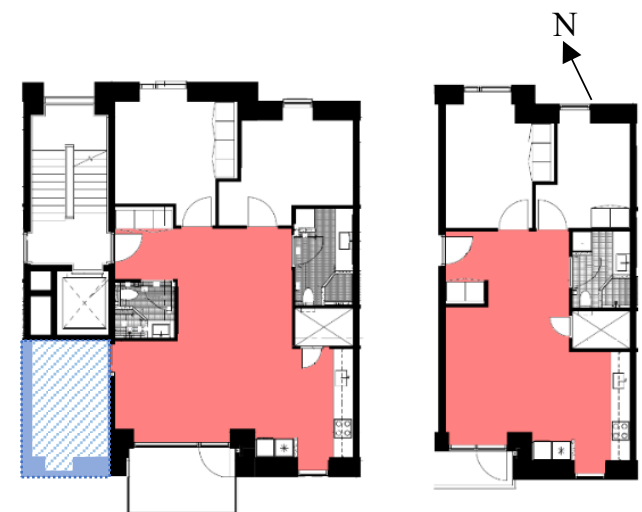

Fig. 1. Representative floor plans: living room type 1 with blue hatched $3^{\text {rd }}$ bedroom (left), living room type 2 (right)

practically decrease the heating setpoint to $12^{\circ} \mathrm{C}$, which triggers a heat cut-off. In the period where data was recorded, the system failed to restitute the latest setpoint after the balcony door was closed, and automatically reset the setpoint to $21^{\circ} \mathrm{C}$.

This study focuses on indoor conditions and occupant behavior in the living room (colored on Fig. 1).

\subsection{Data description}

Two sources of data were used. The first dataset came from a number of sensors that were set up in the eight investigated apartments. Data was collected in the occupied apartments from January $18^{\text {th }}$ to April $30^{\text {th }} 2018$, covering part of a heating season. An overview of the data collected from these sensors is presented in Table 2.

The second source of data was qualitative data collected during interviews carried out with occupants of three of the eight apartments (A, B and C). Interviews with Occupants A and B were carried out in person while the interview with Occupant $\mathrm{C}$ was carried out over the telephone. The interviews were semi-structured and the data consisted in interview transcripts. An interview guide was built in advance, with points of interest to touch upon gathered in four categories: personal background and moving process; opinion of the apartment; technical installations; control possibilities and smart systems. The interviews were carried out in Danish.

\subsection{Data preparation and processing}

As described earlier, a balcony door opening was identified in the setpoint data by a data point at $12{ }^{\circ} \mathrm{C}$, followed by a data point at $21^{\circ} \mathrm{C}$ when the door was closed again. The decrease of setpoint to $12{ }^{\circ} \mathrm{C}$ was excluded from the data, and the point at $21{ }^{\circ} \mathrm{C}$ was also excluded if another setpoint change was recorded within the 6 hours following the closing of the balcony door. Past

Table 2. Overview of the data collected from sensors

\begin{tabular}{|l|l|}
\hline Data type & Frequency of data points \\
\hline Air temperature $\left({ }^{\circ} \mathrm{C}\right)$ & Every 5 minutes \\
\hline Temperature setpoint $\left({ }^{\circ} \mathrm{C}\right)$ & Triggered by a change \\
\hline Balcony door opening & Triggered by a change \\
\hline Heating valve opening status & Every 15 minutes \\
\hline
\end{tabular}


this period, it was considered that the occupant had deliberately let the setpoint decrease to $21^{\circ} \mathrm{C}$, and therefore this change was recorded as a behavioral feature.

When comparing the occurrence of punctual events (window openings, changes in setpoint) with temperature data (collected at fixed intervals), the last value of the temperature was brought forward and given the timestamp of the punctual event.

The interviews were recorded and transcribed manually. The transcribed interviews were loaded into the qualitative data analysis software MaxQDA and coded.

\subsection{Simple neutral temperature estimation}

The method for estimating occupants' neutral temperature presented here is based almost literally on the adaptive principle: "if a change occurs such as to produce discomfort, people react in ways which tend to restore their comfort" [9]. Focus was put on setpoint changes in the heating season, explaining them in this model by a proportional discomfort. The idea behind this theory is the following: the larger the discomfort, the larger the setpoint change, and therefore a large setpoint change implies that the neutral temperature is far from the current indoor temperature. As a result, the relation between the indoor temperature $T_{\text {ind }}$ and the corresponding positive or negative setpoint change $\Delta T_{\text {set }}$ was approximated by a linear relation:

$$
T_{\text {ind }}=a \times \Delta T_{\text {set }}+T_{n}
$$

The neutral temperature $T_{n}$ is the temperature at which there is no need for a setpoint change (the intercept of the linear relation).

The slope and intercept were obtained by performing a linear regression on the sensor data points.

It is however shown in literature that multiple factors impact occupants' feeling of comfort on top of the indoor air temperature: radiant surface temperature, air speed, metabolic rate, clothing level and relative humidity in Fanger's PMV model [8], or outdoor temperature in the adaptive comfort theory [9]. Since the goal of this paper is to estimate comfortable indoor conditions by using easily available data, these parameters were not considered in the present model. Therefore, the calculated neutral air temperature must be complemented by a comfort range in which occupants can feel comfortable depending on the value of the previously mentioned factors. The following section will propose different possible ranges, calculated as different inter-percentile ranges of the distribution (central $50 \%$ to $90 \%$ ranges).

\section{Results}

\subsection{General picture of indoor temperature}

Fig. 2 show the probability density functions (PDF) of the indoor air temperature for the 8 apartments. Even though the considered living rooms are similar in size and

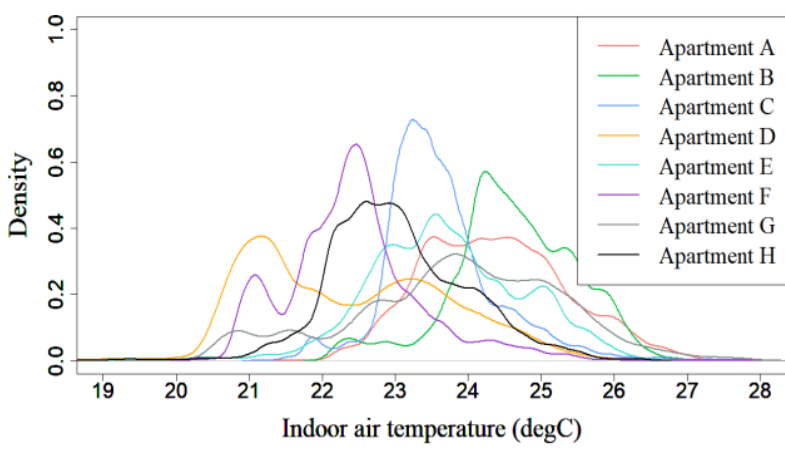

Fig. 2. Probability density functions of indoor air temperature in the living room

orientation, the observed indoor air temperature distributions are very variable. Apartment $\mathrm{C}$ has a very narrow temperature distribution, and so do Apartments B and $\mathrm{F}$ to a lesser extent. Some apartments show large temperature variations along the winter, as Apartments D and G. In Apartments A, E and H, most of the winter is spent in a 3-degree temperature range. The average indoor air temperature varies a lot from apartment to apartment. These dissimilarities can partly be explained by the differences exposed in Table 1, but are also a reflection of differences in occupancy (number of occupants and schedules), as well as the occupants' different preferences and heat control strategies.

\subsection{Simple neutral temperature estimation}

Fig. 3 shows the setpoint changes performed during the winter season and the indoor temperature at which they were performed. The regression line is shown, as well as the calculated neutral temperature $T_{n}$. Several potential comfort ranges are shown, represented at the intersection of the colored regions (inter-percentile ranges corresponding to the central $50 \%$ to $90 \%$ ranges of the distribution) with the $\mathrm{x}$-axis.

The $y=-x$ line (black dotted line) is also drawn (for reasons of visibility, the $\mathrm{x}$ and $\mathrm{y}$ axes have different scales), representing the following situation: if one feels two degrees too cold, one increases the heating setpoint by two degrees (no matter what the original setpoint was and how it compares to indoor temperature). The slope of the regression line for all eight apartments seems to show that occupants react much more strongly to uncomfortable indoor temperatures. One explanation to this slope is the defective reset of the heating setpoint after a window opening, probably making large setpoint increases and decreases (to and from $21{ }^{\circ} \mathrm{C}$ ) more frequent than normally - even though the data filtering described in Section 2.3 partially eliminates this bias.

The steep regression slope is also due to the fact that for all apartments, there is a range of temperatures around the neutral temperature where both positive and negative setpoint changes are registered. This shows that many factors influence one's comfort perception and actions on heating, which will be investigated further in this article.

Even though they were recorded during the same period, the number of setpoint changes varies a lot from apartment to apartment. The 8 cases can be grouped in 3 

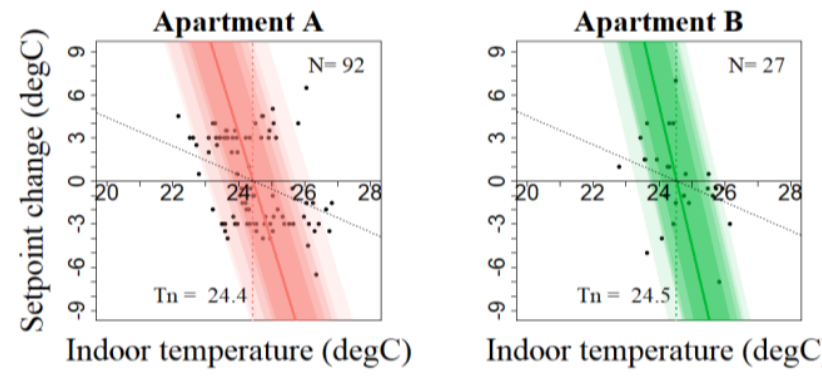

Indoor temperature $(\operatorname{deg} C)$

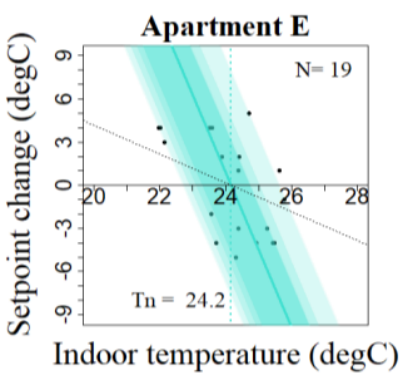

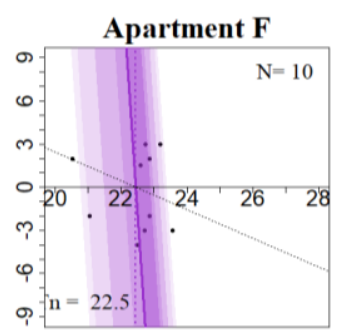

Indoor temperature $(\operatorname{deg} C)$

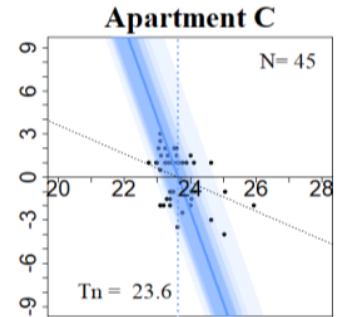

Indoor temperature $(\operatorname{deg} C)$

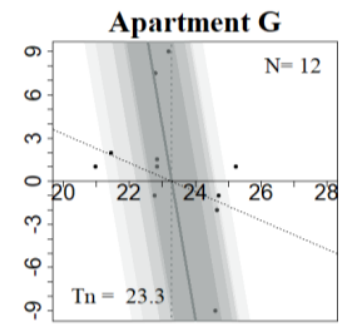

Indoor temperature $(\operatorname{deg} C)$

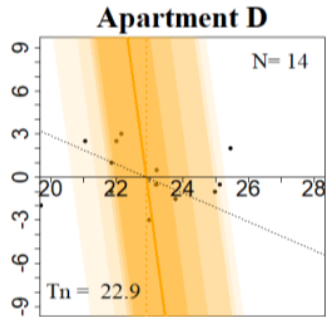

Indoor temperature $(\operatorname{deg} C)$

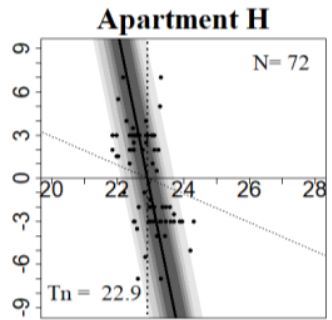

Indoor temperature $(\operatorname{deg} C)$

Fig. 3. Amplitude of setpoint changes, corresponding indoor temperature and neutral temperature estimation

categories: apartments with many setpoint changes and a small spread $(\mathrm{C}$ and $\mathrm{H})$, apartments with few setpoint changes and a large spread (B, D, E, F and G) and apartments with many setpoint changes and a large spread (A).

The first category could be interpreted as occupants with a large level of control of their indoor environment and precise expectations from it, who are able to adjust the setpoint to fit their well-defined preferences. The second category can be seen as occupants with a larger acceptability or larger adaptation capacity, who do not consider that they need to act more on their indoor environment to be comfortable. The third category seems to reflect an occupant with a very active interaction with the floor heating system, but who does not achieve a stable temperature, which may reveal a misfit between the occupant's wishes and the performance provided by the heating system. The next section will investigate further one apartment in each of these categories (A, B, and C).

\subsection{Further explanation of setpoint changes}

\subsubsection{Analysis of setpoint and window opening data}

Fig. 4 shows the actual setpoint changes and the indoor temperature at the moment of the change for Apartments A, B and C. Setpoint changes are represented by an arrow from the original setpoint to the final setpoint. Blue arrows represent a setpoint decrease while red arrows represent a setpoint increase. In the red area, heat is on $\left(T_{\text {set }}>T_{\text {ind }}+0.5^{\circ} \mathrm{C}\right)$ while it is off in the blue area. The middle zone shows the heating dead-band.

In all three apartments, a large part of the setpoint changes occur from or to $21^{\circ} \mathrm{C}$, which in most cases corresponds to a balcony door opening without setpoint adjustment during 6 hours after the closing. This can to some extent be interpreted as a negligence from occupants (and therefore constitute a bias in the data), but can also be seen as a deliberate strategy to cool down the apartment for a period. An element supporting this last hypothesis is the small share of setpoint decreases that do not end at $21^{\circ} \mathrm{C}$ : 13 (25\%) for Apartment A, 3 (20\%) for Apartment $\mathrm{B}$ and $5(24 \%)$ for Apartment $\mathrm{C}$ : not increasing the setpoint after a window opening is the main way to decrease indoor temperature.

Occupant $\mathrm{A}$ is from far the one interacting the most with heating setpoints. However, most of these interactions consist in changes from $21^{\circ} \mathrm{C}$ to $24^{\circ} \mathrm{C}$ and back, which mainly shows that Occupant A did not restore the original setpoint shortly after a window opening, but still had a routinized practice of setting it back to $24^{\circ} \mathrm{C}$. She did so even when this action did not result in turning heat on (when the indoor temperature was already above $\left.23.5^{\circ} \mathrm{C}\right)$.

For indoor temperatures below the calculated neutral temperature, a subsequent part of the setpoint increases (57\% for Apartment A, 56\% for Apartment B and 30\% for Apartment $\mathrm{C}$ ) result in turning heat on by setting the setpoint more than $0.5^{\circ} \mathrm{C}$ above indoor air temperature. In many cases, this implies increasing the setpoint above the usually chosen setpoint, which shows a deliberate attempt to turn heat on. This is an additional explanation to the steep slope of the regression lines drawn in Fig. 3: when feeling cold, occupants increase the heating setpoint until triggering the opening of the floor heating valve, in order to achieve a change. Apartment $\mathrm{C}$ is the one with the largest number of setpoint increases that do not start from $21^{\circ} \mathrm{C}$, potentially revealing a dissatisfaction with the current setpoint and a search for a better option.

Fig. 5 shows the probability density function of indoor air temperature when only considering the time points when occupants open the living room window (balcony door) for more than 3 minutes (colorful bars and curve). The gray bars and curve represent the overall probability density function of indoor air temperature on the considered period (it is the same data as on Fig. 2). In Apartments $\mathrm{A}$ and $\mathrm{B}$, the distribution of points corresponding to a window opening has a similar shape to the general distribution, but shifted by about $1.5^{\circ} \mathrm{C}$ 

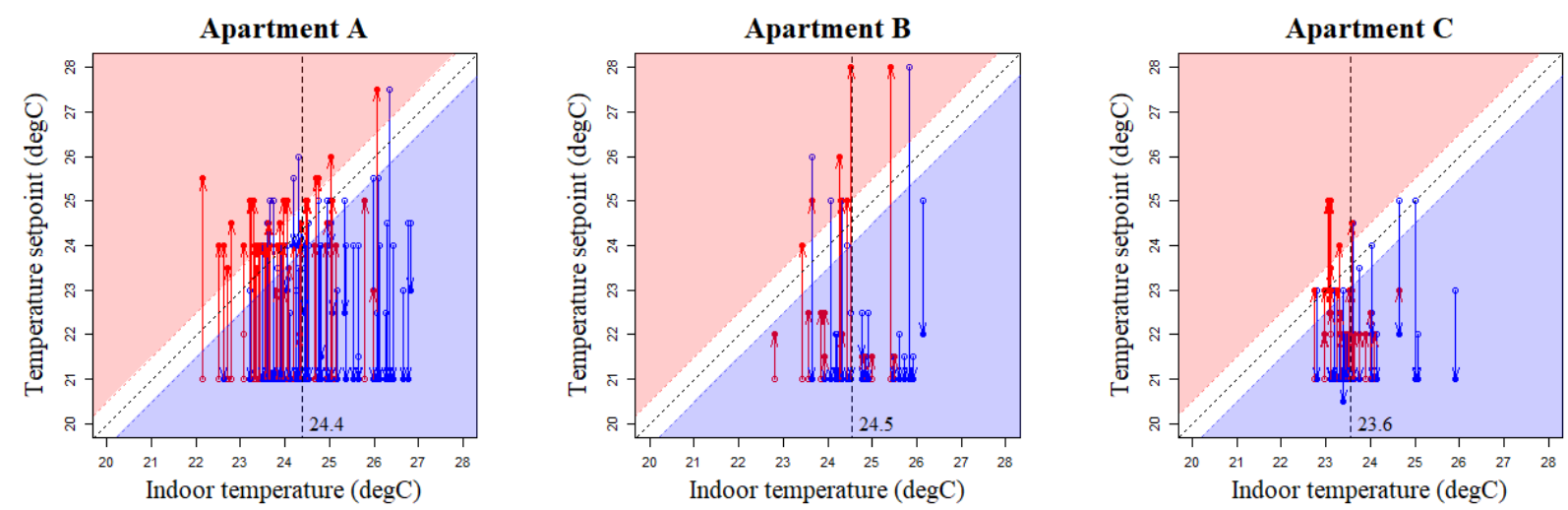

Fig. 4. Temperature setpoint, corresponding indoor temperature and calculated neutral temperature

towards warmer temperatures, showing that warm indoor temperatures are a trigger to window opening. In Apartment $\mathrm{C}$, the distribution in temperature of window openings is more spread than the general distribution, showing an overrepresentation of window openings for cold indoor temperatures, as well as for warm indoor temperatures (window opening is then expected to be a consequence of warm conditions).

\subsubsection{Further insights from interviews}

Occupant A used to live in a house with radiators, and she had difficulties adapting to the long time constant of floor heating. She felt this had to a certain extent discouraged her from regulating heating via the setpoint panel:

"But I haven't used it [the panel] a lot. Because there go so many hours before it works. So I just put on a sweater" - Occupant A

She also kept mentioning "turning on" and "turning off" floor heating. She was not very familiar with the idea of setpoint, and attached importance to the floor being warm as an indicator of the system working as expected.

"I mean, it has to be really cold for me to turn it on. It is not so often that I have it on in the living room. [...] Even though I think it would be nice, if the floor was warm sometimes." - Occupant A

She acknowledged sometimes forgetting to increase the setpoint again after closing the window.
"Sometimes I say okay, I try to turn it on. So it is on, and then, because, you know, I need some fresh air, or to use the balcony, I open the door and then I forget I turned it on, and so it is back to $21^{\circ}$ C" - Occupant A

She also mentioned having to open windows in the winter to cool the house down due to regulating problems:

"For example, I had turned it on, and then my children came to visit, and it was just so warm that they had to open the windows to just be able to...

- In the middle of the winter?

- Yes! [laughs] Because, I mean when it becomes 26-27 degrees, it is just too warm"

\section{- Occupant A}

Occupant B understood perfectly how heating was regulated based on indoor temperature. She was not particularly enthusiastic about it, but did not consider it a big issue - and did not mention the large time constant as a problem either.

"I mean. It works the way it should... but there is no guarantee to get heat. Or you should turn it up higher than air temperature [laughs]. And then there would only be heat in the floor as long as the air temperature is below, right. It is a bit...but I mean, it is fine, it is the right way to save energy - floor heating, I mean". - Occupant B

She chose to operate all rooms at the same temperature, meaning that the common setpoint could be chosen based on conditions in any room.
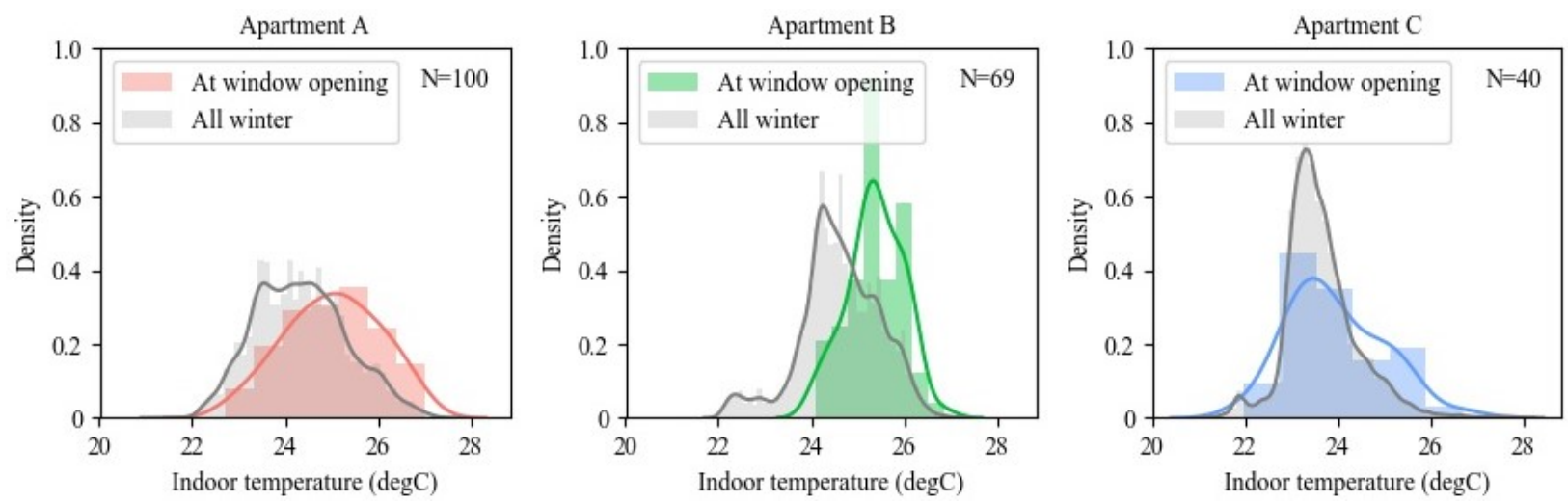

Fig. 5. Probability density function of indoor temperature all winter long (grey) and at the moment occupants open windows (color) 
"We run the whole house with the same temperature. Yes, I think it somehow makes more sense than if you for example set a higher temperature in the bathroom - if you leave the door open then it keeps running in there."

\section{- Occupant B}

Occupant B also showed an interest in finding alternative ways to get fresh air without having to open the windows, in order not to waste energy. She found it in the small openings present on top of all windows:

"We do have to get some fresh air inside, and I think that it [venting openings] is a very nice way to get a little bit of air inside without getting too much, right, without having to open the window and so on. We have a lot of those that we can open." - Occupant B

Occupant $\mathrm{C}$ had difficulties regulating the temperature. The main problem according to her was the temperature asymmetry within the living room:

"It is a bit as if it was either on or off. So...close to the window, it is typically cold, and then you have to increase the temperature [setpoint] a lot before it starts to heat, and then it is almost too warm in the apartment." - Occupant C

Occupant $\mathrm{C}$ therefore did not manage to find the setpoint guaranteeing the most comfortable solution. She tried different setpoints one after the other but without result so far.

"We have tried to increase by half a degree at a time, and then say, we try half a degree higher for three-four days and see how it works. So suddenly it turns on, and so it just gets really warm in the apartment. We tried to [...] be a bit patient. But I mean, we had a sauna for three days [laughs]. On the fourth day [we said]: no, it just doesn't work."

\section{- Occupant C}

Occupant $\mathrm{C}$ had a defective ventilation system for a period, and therefore she had to open windows to get fresh air - which can explain the spread distribution on Fig. 5.

"I have opened the window and I often create a draft, because ventilation doesn't work so well. [...] In winter I just do it for a shorter time [laughs]" - Occupant C

\subsubsection{Conclusion on heating regulation}

A deeper analysis of setpoint changes and of occupants' own words reveal a number of factors other than temperature-induced discomfort with an influence on occupants' interaction with heating systems, and that should be included in setpoint change interpretation.

The complementary data regarding Apartment A confirms the hypothesis formulated based on Fig. 3: Occupant A has difficulties controlling the indoor temperature by adjusting setpoints. The main problem for her lies in the long response time of the floor heating system. Occupant B did not express particular concerns regarding the heating system and has understood that she is not expected to interact much with setpoints. The interpretation made out of Fig. 3 regarding Apartment $\mathrm{C}$ shows to be partially wrong: even though there is little temperature variation in the living room according to the sensor data, Occupant $\mathrm{C}$ experiences temperature asymmetry within that room, which results in dissatisfaction and frustration towards heating control.

In this precise building, technical failure of the setpoint panel after window closing has a large influence on the number and nature of setpoint changes. Routine is also a factor to consider and to identify from the data. It is important as well to acknowledge that some occupants are not familiar with the concept of setpoint, and will adjust them just enough to "turn on" or "turn off" heating.

\subsection{Application: flexibility potential}

A simple scheme for "desirable flexible behavior" of apartments connected to the Copenhagen district heating system has been examined by the greater Copenhagen utility HOFOR as part of the EnergyLab Nordhavn project [19]. In this work, they define two periods for typical peak hours (06-09.00, and 17-20.00) where shifting of load to off-peak hours would be beneficial in terms of both system cost and environmental impact - the peak load currently being covered by expensive and polluting fossilfired burners.

Fig. 6 shows the $10-90 \%$ temperature quantiles for all days in the period divided into 30-minute intervals (red). Also shown is the total number of valve openings of the living room floor heating system (blue) and the positive setpoint changes of the occupants in the living room (green). The valve openings represent the moments of the day where the floor heating system is used - and thus where there is a potential for flexible consumption. The setpoint change bars show at what time occupants are actively trying to restore comfort by acting on the heating system. The temperature quantiles show the temperatures for all hours of the days in the period.

Apartment A shows a much more frequent valve opening than the other two. Two hypotheses can explain this: the overall higher setpoint chosen (leading to valve openings particularly at night when indoor temperature drops below setpoint) and the frequent alternation in setpoint between $21^{\circ} \mathrm{C}$ and a higher value (Fig. 4).

For Apartments $\mathrm{A}$ and $\mathrm{C}$ the patterns of valve openings have a pronounced dip during mid-day, which corresponds both to unoccupied hours and periods of high solar irradiance. For Apartment B the dip is less pronounced, and there are no valve openings at night. The temperature distribution shows that the temperature in the living room is close to the identified neutral temperature for all the apartments, but also that there is a certain variation and a tendency to overheating in the afternoon.

Fig. 6 also shows that for the apartments under investigation, the habit of increasing the heating setpoint in the morning is in direct conflict with the desirable behavior as seen from the district heating system. Temperature tends to fall at night, and is in average below the neutral temperature as occupants get up in the 

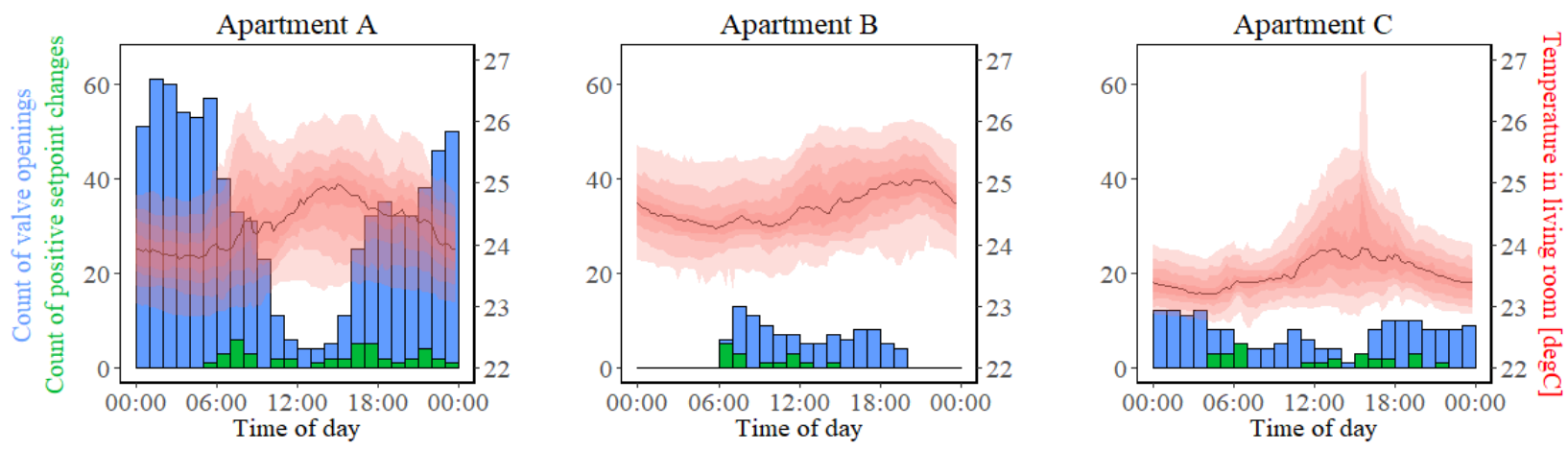

Fig. 6. Count of 15-minute valve openings in floor heating circuit (blue), count of positive setpoint changes by occupants (green) and daily temperature $10-90 \%$ quantiles (red) in the living room calculated for 30-minute windows.

morning. This suggests that the idea of pre-heating the building as a way to shift load by starting heating in the night would have the dual benefit of bringing the room closer to the neutral temperature in the morning and shifting peak load to a more beneficial hour of the day. Thus, shifting load to the night hours for Apartments A and $\mathrm{C}$ would potentially lead to an increase in comfort.

For Apartment B the current control strategy of the floor heating system causes it to place all heating during the daytime. Indeed, when only looking at the last setpoint chosen every day, it is seen that $94 \%$ of them are lower than $22.5^{\circ} \mathrm{C}$, while this temperature is never reached at night - therefore no activations are registered at night. For this apartment the synergetic effect of heating earlier is thus even more relevant than for Apartments A and C.

A re-design of the control strategy of the floor heating system based on e.g. fixed hour pre-heating could easily and cost-effectively be implemented for the apartments under investigation. This would have the potential benefit of reducing the load on the district heating system as well as limiting overheating. This is currently being tested in the apartments in Copenhagen.

Such a system would however not respect the neutral temperature for those times where the temperature is in fact too high in the morning, which we can see from Fig. 6. A more sophisticated approach would be to use a dynamic measure of the neutral temperature in combination with forecasted values for the indoor climate as it is done in e.g. predictive control methods. Combining the simple time-based load shifting strategy with Model Predictive Control (MPC) could lead to e.g. a full economic MPC where the needs of the district heating system are captured by a forecasted dynamic heating price. The proposed control strategy design is shown in
Fig. 7. The development of such a control system to the point of implementation is an ongoing work in the EnergyLab Nordhavn project.

\section{Discussion}

Due to the small size of the dataset used in this example, no general conclusions can be reached about occupant behavior in low-energy homes, and the factors mentioned in Section 3.3. to nuance the interpretation of setpoint change constitute by no means an exhaustive list. The insights shown here are also very case-dependent; in particular, the faulty setpoint setback certainly had a large influence on the dataset. This issue is now fixed in most apartments, therefore future data collection in the same building will be more true to the occupants' wishes.

This work is a preliminary study exposing the method, potential applications and directions for developing the concept further. Future work will be based on a larger number of apartments and a longer collection period. More interviews will also be carried out until theoretical saturation is reached [20], and the possible biases observed will be integrated in the model. A more thorough investigation of the heating strategy employed in the apartments, also including data from adjacent rooms, would possibly reveal more insight into the differences in heating that take place in very similar apartments.

Distinguishing different setpoint-indoor temperature relations depending on outdoor conditions, as suggested by the adaptive comfort theory, is considered for future investigations. Investigating the relation of setpoint changes to existing comfort metrics, such as predicted mean vote, is also envisaged.

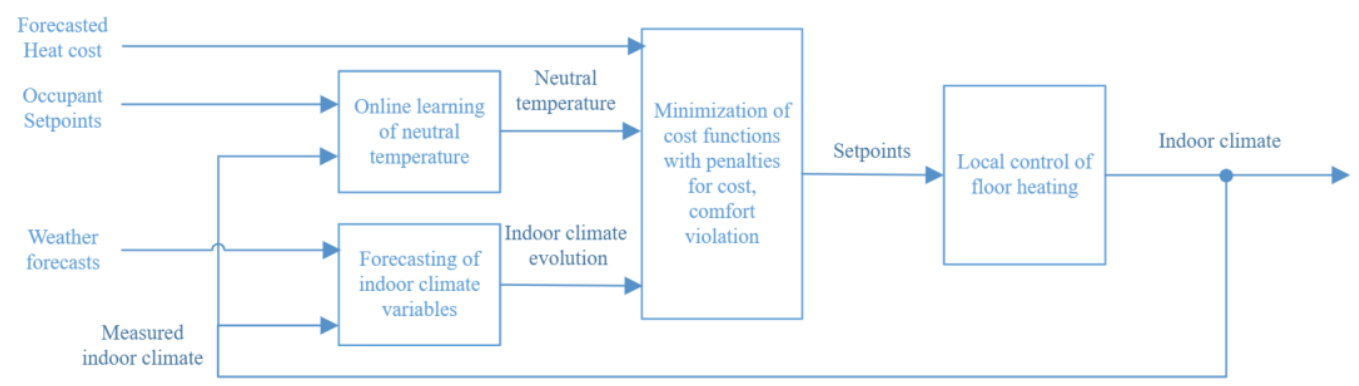

Fig. 7. Generic control system architecture to account for dynamic occupant neutral temperature, district heating needs and energy efficiency 


\section{Conclusion}

This study puts forward a simple method to estimate residential building occupants' winter neutral temperature based on data that is expected to be largely available in the close future due to the spread of smart home thermostats: setpoint change data. Setpoint change amplitudes are used as a measurement of discomfort and neutral temperature is calculated accordingly. This simple method is followed by an analysis of the mechanisms behind setpoint changes in three newly built low-energy apartments as well as a study of window openings as temperature regulation. Finally, the consequences of the highlighted heating behavior on energy flexibility potential provided by these apartments are put in light.

The case study permits to link setpoint adjustment behavior with thermal preference and to distinguish three occupant types. This article also highlights several instrumental factors to take into account when refining this method. Window openings are to some extent used as temperature regulation tools in the heating season and must be included in the model. Making heating technology in low-energy building more user-friendly is a necessity, not only for occupants' own well-being but also in order to be able to use setpoint data to define comfort and plan for flexible operation of buildings. Educating occupants to these new systems can contribute to a smoother, more reliable and more sustainable building design and operation.

This work is funded by Saint-Gobain Denmark, Innovationsfonden and Realdania as part of the first author's $\mathrm{PhD}$ project. The data collection was carried out in the context of the research project EnergyLab Nordhavn funded by EUDP.

\section{References}

[1] European Commission. Statistical Office of the European Union., Shedding light on energy in the EU a guided tour of energy statistics (2018)

[2] Transport- Bygnings- og Boligministeriet, Bekendtgørelse om bygningsreglement 2018 (2018)

[3] S. D'Oca, T. Hong, and J. Langevin, The human dimensions of energy use in buildings: A review, Renew. Sustain. Energy Rev., 81, pp. 731-742 (2018)

[4] P. Hoes, J. L. M. Hensen, M. G. L. C. Loomans, B. de Vries, and D. Bourgeois, User behavior in whole building simulation, Energy Build., 41, 3, pp. 295-302 (2009)

[5] R. Andersen, The influence of occupants' behaviour on energy consumption investigated in 290 identical dwellings and in 35 apartments, Abstr. from 10th Int. Conf. Heal. Build., May, pp. $1-3(2012)$

[6] S. Andersen, R. K. Andersen, and B. W. Olesen, Influence of heat cost allocation on occupants' control of indoor environment in 56 apartments: Studied with measurements, interviews and questionnaires, Build. Environ., 101, pp. 1-8 (2016)
[7] H. N. Knudsen, K. E. Thomsen, and O. Mørck, Occupant experiences and satisfaction with new low-energy houses, Proc. Clima 2013 11th REHVA World Congr. Energy Effic. Smart Heal. Build. (2013)

[8] P. O. Fanger, Thermal Comfort-Analysis and Applications in Environmental Engineering. Copenhagen: Danish Technical Press (1970)

[9] J. F. Nicol and M. A. Humphreys, Adaptive thermal comfort and sustainable thermal standards for buildings, Energy Build., 34, 6, pp. 563-572 (2002)

[10] R. de Dear, J. Kim, and T. Parkinson, Residential adaptive comfort in a humid subtropical climate-Sydney Australia, Energy Build., 158, pp. 1296-1305 (2018)

[11] Y. Song, Y. Sun, S. Luo, Z. Tian, J. Hou, J. Kim, T. Parkinson, and R. de Dear, Residential adaptive comfort in a humid continental climate Tianjin China, Energy Build., 170, pp. 115-121 (2018)

[12] L. Peeters, R. de Dear, J. Hensen, and W. D'haeseleer, Thermal comfort in residential buildings: Comfort values and scales for building energy simulation, Appl. Energy, 86, 5, pp. 772780 (2009)

[13] J. Kim, S. Schiavon, and G. Brager, Personal comfort models - A new paradigm in thermal comfort for occupant-centric environmental control, Build. Environ., 132, pp. 114-124 (2018)

[14] J. Farrokh, G. Ali, B.-G. Burcin, K. Tatiana, and O. Michael, Human-Building Interaction Framework for Personalized Thermal ComfortDriven Systems in Office Buildings, J. Comput. Civ. Eng., 28, 1, pp. 2-16 (2014)

[15] L. Jiang and R. Yao, Modelling personal thermal sensations using C-Support Vector Classification (C-SVC) algorithm, Build. Environ., 99, pp. 98106 (2016)

[16] A. Ghahramani, C. Tang, and B. Becerik-Gerber, An online learning approach for quantifying personalized thermal comfort via adaptive stochastic modeling, Build. Environ., 92, pp. 8696 (2015)

[17] B. Huchuk, W. O'Brien, and S. Sanner, A longitudinal study of thermostat behaviors based on climate, seasonal, and energy price considerations using connected thermostat data, Build. Environ., 139, pp. 199-210 (2018)

[18] D. P. Wyon and J. E. Ridenour, A covert fieldintervention experiment to determine how heating controls that conserve energy affect thermal comfort, Indoor Air, 28, 5, pp. 763-767 (2018)

[19] C. Sandersen and K. Honoré, District heating flexibility - short term heat storage in buildings, pp. 1-30 (2018)

[20] B. Saunders, J. Sim, T. Kingstone, S. Baker, J. Waterfield, B. Bartlam, H. Burroughs, and C. Jinks, Saturation in qualitative research: exploring its conceptualization and operationalization, Qual. Quant., 52, 4, pp. 18931907 (2018) 